\title{
Recurrent Acute Leukemia
}

National Cancer Institute

\section{Source}

National Cancer Institute. Recurrent Acute Leukemia. NCI Thesaurus. Code C148429.

The reemergence of acute leukemia after a period of remission. 